\title{
Comparison of dietary and non-dietary risk factors in overweight and normal-weight Chinese adults
}

\author{
Gang $\mathrm{Hu}^{1}$, Heikki Pekkarinen ${ }^{1}$, Osmo Hänninen ${ }^{1}$, Huiguang Tian ${ }^{2}$ and Rongpei Jin ${ }^{2}$ \\ ${ }^{1}$ Department of Physiology, University of Kuopio, Kuopio, Finland \\ ${ }^{2}$ Food Safety Control and Inspection Institute Tianjin, Tianjin, The People's Republic of China
}

(Received 6 December 2000 - Revised 31 August 2001 - Accepted 15 February 2002)

\begin{abstract}
The aim of the present study was to compare the differences in dietary and non-dietary factors contributing to normal weight and overweight among urban Chinese adults. Two cross-sectional population surveys were carried out in Tianjin, one of the largest cities in China. A total of 2631 subjects aged 25-64 years were selected by random stratified cluster sampling; 398 men and 490 women were overweight, and 886 men and 857 women were of normal weight. The diet was assessed by food weighing plus consecutive individual $3 \mathrm{~d}$ food records. Health-related behaviours and anthropometry were assessed. The overweight group had significantly higher mean daily intakes of energy and carbohydrate than the normal-weight group. Overweight men also had significantly higher mean daily intakes of protein and fat than normal-weight men. Age, daily intakes of energy and carbohydrate, and marital status were positively associated with overweight, while occupational and commuting physical activity, as well as smoking, were inversely associated with overweight among both genders. Daily intakes of protein, fat and alcohol were positively related to the incidence of being overweight among men. People with 7-12 years education were more likely to be overweight compared with those with less than 6 years of education. High intakes of energy and carbohydrate among both genders, as well as high intakes of protein and fat among men, and lower levels of occupational and commuting physical activity, being a non-smoker, and partly higher socio-economic status were related to a greater incidence of being overweight in this population.
\end{abstract}

Risk factors: Overweight: Chinese adults

China is the largest developing country in the world. In recent years, following the rapid economic development with good food supply, people have gradually changed their lifestyle and food habits. Lifestyle change in the population has increased the incidences of overweight and obesity (Popkin et al. 1995). In Tianjin, located in north China and the third largest city in the country, the prevalence of overweight was more than $30 \%$ in the mid 1980s (Tianjin Public Health Bureau, 1993).

Obesity is not only associated with a number of cardiovascular risk factors including hypertension, high serum cholesterol, insulin resistance and hyperinsulinaemia, but is also an independent risk factor for CHD (Hubert et al. 1983; Wood, 1994; Stunkard, 1996; Mertens \& Gaal, 2000). Cardiovascular diseases have quickly become the main causes of death in urban China (Yao et al. 1993; Cheng, 1998; Reddy \& Yusuf, 1998). In Tianjin, the deaths caused by stroke and heart diseases accounted for
$51-56 \%$ of mortality in the mid 1980s (Tianjin Public Health Bureau, 1993).

In order to prevent and control chronic diseases, The Tianjin Project, which is the first major project aiming at prevention and control of chronic diseases in China, was launched in 1984 (Tianjin Public Health Bureau, 1993). Two independent cross-sectional surveys were carried out in 1989 and 1992. The population survey provided an opportunity for us to assess dietary and non-dietary risk factors for different body-weight patterns. The aim of the present article is to clarify the main dietary and non-dietary risk factors for being overweight and of normal weight among urban Chinese adults.

\section{Materials and methods}

The baseline survey was carried out in 1989 and another survey in 1992. These surveys were cross-sectional studies.

\footnotetext{
Abbreviation: SES, socio-economic status.

* Corresponding author: Dr Gang Hu, present address, Department of Epidemiology and Health Promotion, National Public Health Institute, Mannerheimintie 166, FIN-00300 Helsinki, Finland, fax +358 94744 8338, email hu.gang@ktl.fi
} 
The city of Tianjin has a population of 9.5 million, of whom 4 million people live in the six urban districts. Random stratified cluster sampling was employed in these surveys. First, streets were selected from the six districts. Then, resident sections in each street were chosen for the survey. Finally, individuals were drawn from the local population registers in the sampled resident sections. A total of 1205 subjects completed the survey in 1989 and 1426 subjects in 1992 . The age range in the two surveys was 25-64 years. The response rates were $97 \%$ in 1989 and $96 \%$ in 1992 . We divided the population into two groups by BMI. In the normal-weight group, there were 427 men and 390 women in 1989, and 459 men and 467 women in 1992. In the overweight group (overweight was defined as BMI $\geq 25$ ) (Popkin et al. 1995; Yu et al. 1999) there were 174 men and 214 women in 1989, and 224 men and 276 women in 1992. In total there were 886 men and 857 women of normal weight, and 398 men and 490 women who were overweight.

The surveys included a nutrition survey, a questionnaire and anthropometric measurements. The questionnaire, which mainly dealt with aspects of socio-economic status (SES), health status, health behaviour and health knowledge, was completed by home interview. Commuting and leisure-time physical activity were assessed only in 1989. Height and weight were measured. The data were collected using the same methods in 1989 and 1992. Health workers conducted the survey. All observers were intensively trained before the field survey.

The methods used for assessing the diet were food weighing plus $3 \mathrm{~d}$ food records. About 100 health workers took 2 months to complete the dietary surveys in each year. Details of the dietary methods have been published (Tian et al. 1995b). Standardized weighing scales recording up to $5 \mathrm{~kg}$ (accuracy $0.01 \mathrm{~kg}$ ) were used for weighing most of the foods, and weighing scales recording up to $0.5 \mathrm{~kg}$ (accuracy $0.001 \mathrm{~kg}$ ) were used for weighing salts, monosodium glutamate and sodium carbonate. The survey started by measuring and recording all foods in each household including raw materials, processed foods and home production after supper on the first day of the survey. Then individual food intake was recorded for three consecutive days. A single amount was used for each person to record food intake data; however, for the foods shared with others at home, the amounts were collected by estimating portion size using the bowls and plates. The health workers visited the households after supper on the second day of the survey. They checked individual food records and recorded foods bought. On a $24 \mathrm{~h}$ recall basis, the health workers collected the data from the persons who ate at home but did not keep food records. Food waste was estimated whenever weighing was not possible. The same procedure was repeated for $3 \mathrm{~d}$. All foods were weighed again on the fourth day of the survey after collecting the $3 \mathrm{~d}$ food records. The total individual food estimations were reconciled with the foodweighing data by adjusting the sum of the $3 \mathrm{~d}$ food records according to the weighed household consumption of supplies. For instance, according to the food record data, a total of $3.0 \mathrm{~kg}$ cabbage was consumed by two persons in one household, one person consuming $1.0 \mathrm{~kg}$, the other eating $2.0 \mathrm{~kg}$; but according to the food weighing results, a total of only $2.4 \mathrm{~kg}$ cabbage was consumed, not $3.0 \mathrm{~kg}$. The extra $0.6 \mathrm{~kg}$ cabbage was reduced proportionately from the amount of individual consumption. Therefore, the final results for cabbage consumption were $0.8 \mathrm{~kg}$ for one person and $1.6 \mathrm{~kg}$ for the other. Intakes of energy and nutrients were analysed using the Chinese food composition tables (Preventive Medicine Academy of China, 1991).

Height and weight measurements were taken using a stadiometer and beam balance scale with subjects wearing usual light indoor clothing without shoes. Height and weight were measured twice, and the mean values of the readings were used for the analysis. BMI was calculated by dividing the subject's weight $(\mathrm{kg})$ by the square of the height $(\mathrm{m})$.

Smoking was assessed using a set of questions in the questionnaire. Based on the response, the participants were classified into two categories: (1) current smokers were subjects who had smoked regularly and smoked a mean of at least one cigarette per d during the past $30 \mathrm{~d}$; (2) the remaining subjects were considered as ex-smokers and those who had never smoked.

Alcohol consumption was calculated from the food intake data and converted into $\mathrm{ml}$ absolute alcohol/d.

Information on SES was collected via questionnaires. The number of years of education were divided into three categories: $0-6$ years, $7-12$ years, $>13$ years. According to the reported average monthly income per capita of the participant's family, expressed as yuan (US $\$ 1=8.3$ yuan), income was grouped into three categories: low ( $<70$ yuan), medium ( $70-90$ yuan), high ( $>90$ yuan). Marital status was dichotomized as married or single, with the latter including unmarried, divorced, and widowed individuals.

Physical activity was assessed using a questionnaire. Physical activity included occupational, commuting and leisure-time exercise. The subjects reported their occupational physical activity according to three class divisions: 'sedentary' was physically very easy, sitting office work and retired or housewife; 'intermediate' was work including standing and walking; 'active' was strenuous work. The subjects were asked if they walked, bicycled or used a bus to and from work, school and shopping, and the duration of these activities. Daily activity of going to and from work was classified into three categories: by bus or no commuting physical activity, on foot $<30 \mathrm{~min}$ or by bicycle $<15 \mathrm{~min}$, and on foot $\geq 30 \mathrm{~min}$ or by bicycle $\geq 15 \mathrm{~min}$. With regard to leisure-time exercise, respondents were asked 'how often do you participate in any physical activity or exercises such as running, dancing, ball sports, Qi Gong, or walking for exercise per week?' Weekly leisure-time exercise was classified into three categories: $>2$ times, $1-2$ times, and $<1$ time or none.

The data were analysed using the SPSS program (1994; SPSS, Chicago, IL, USA). The differences of dietary factors between overweight and normal-weight people were tested by using general factorial ANOVA after adjustment for age, energy (except with energy as dependent variable), education, income, marital status, occupation and time of survey. To assess the association between weight and dietary and non-dietary risk factors, adjusted odds ratios 
were calculated by logistic regression. Analysis of the association between overweight and dietary factors was adjusted for age, energy (except with energy as dependent variable), education, income, marital status, occupation and time of survey. When calculating the odds ratios for risk factors between different levels of categorial variables, dummy variables were created by using lowest group as reference category, i.e. no alcohol use, low education, low income, single, sedentary occupation, no smoking, going to and from work by bus and less than one or no leisure-time exercise episodes.

\section{Results}

First, we compared the means of daily intakes of food, energy and the major nutrients, and subjects' SES, overweight and smoking between two surveys. The results showed that there were no statistically significant differences between the two surveys. Because no significant differences between surveys were found, we pooled the data of the two surveys for further analysis.

The descriptive characteristics of the study samples are presented in Table 1. In general, overweight people were older and were more likely to report having lower levels of commuting physical activity than normal-weight persons. Overweight men were also more likely than normal-weight men to be less educated, to be participating in low occupational physical activity, and to report having higher income and married levels. There was very little difference between normal and overweight women with regard to education, income, married status and occupational physical activity.

The overweight group had significantly higher mean daily intakes of energy $(P<0.001$ in men, $P<0.05$ in women), carbohydrate $(P<0.01$ in men, $P<0.001$ in women) and cereal products $(P<0.05$ in men, $P<0.001$ in women) than the normal-weight group (Table 2). Overweight men also had significantly higher mean daily intakes of protein $(P<0 \cdot 05)$, fat $(P<0.01)$ and nuts $(P<0.05)$ than normal-weight men. The significantly higher mean daily intakes of oil $(P<0.05)$ and sugar $(P<0.05)$, as well as higher \% energy from carbohydrate $(P<0.001)$ were seen among overweight women compared with normal-weight women.

Selected dietary covariates were entered in logistic regression model to explain the risk factors for being overweight (Table 3). After adjustment for age, SES and time of survey, odds ratio/418 kJ $(100 \mathrm{kcal})$ increases in prevalence of overweight were 1.04 (95\% CI 1.02, $1.06)$ in men, and 1.02 (95\% CI 1.02, 1.05) in women. After adjustment for age, energy, SES and time of survey, the odds ratio/ $10 \mathrm{~g}$ carbohydrate increase in prevalence of overweight was 1.02 (95\% CI 1.01, 1.04) in both genders. In men, odds ratios were $1.06(95 \%$ CI $1.01,1.10)$ and $1.06(95 \%$ CI $1.02,1.10) / 10 \mathrm{~g}$ protein and fat increase respectively. Men who drank alcohol had

Table 1. Characteristics of overweight ${ }^{*}$ and normal-weight subjects aged 25-64 years in urban Tianjin, China

(Mean values and standard deviations)

\begin{tabular}{|c|c|c|c|c|c|c|c|c|}
\hline & \multicolumn{4}{|c|}{ Men } & \multicolumn{4}{|c|}{ Women } \\
\hline & \multicolumn{2}{|c|}{ Normal weight } & \multicolumn{2}{|c|}{ Overweight } & \multicolumn{2}{|c|}{ Normal weight } & \multicolumn{2}{|c|}{ Overweight } \\
\hline & Mean & SD & Mean & SD & Mean & SD & Mean & SD \\
\hline Subjects $(n)$ & 886 & & 398 & & 857 & & 490 & \\
\hline Age (years) & 45 & 12 & 47 & 12 & 45 & 12 & 48 & 11 \\
\hline BMI $\left(\mathrm{kg} / \mathrm{m}^{2}\right)$ & 22 & 2 & 28 & 2 & 22 & 2 & 28 & 2 \\
\hline \multicolumn{9}{|l|}{ Education (\%) } \\
\hline $0-6$ years & 20 & & 17 & & 35 & & 36 & \\
\hline $7-12$ years & 67 & & 73 & & 60 & & 59 & \\
\hline$>13$ years & 13 & & 10 & & 5 & & 5 & \\
\hline \multicolumn{9}{|l|}{ Income (\%) } \\
\hline Low & 35 & & 26 & & 36 & & 34 & \\
\hline Medium & 29 & & 30 & & 30 & & 31 & \\
\hline High & 36 & & 44 & & 34 & & 35 & \\
\hline Married (\%) & 83 & & 95 & & 84 & & 92 & \\
\hline \multicolumn{9}{|l|}{ Occupation (\%) } \\
\hline Sedentary & 49 & & 60 & & 54 & & 56 & \\
\hline Intermediate & 9 & & 4 & & 8 & & 8 & \\
\hline Active & 42 & & 36 & & 38 & & 36 & \\
\hline Smoking (\%) & 70 & & 56 & & 21 & & 20 & \\
\hline Alcohol user (\%) & 20 & & 26 & & 10 & & 9 & \\
\hline \multicolumn{9}{|l|}{ Going to/from work per day (\%)† } \\
\hline By bus & 11 & & 20 & & 30 & & 34 & \\
\hline On foot $<30 \mathrm{~min}$ or by bicycle $<15 \mathrm{~min}$ & 19 & & 18 & & 24 & & 36 & \\
\hline On foot $\geq 30 \mathrm{~min}$ or by bicycle $\geq 15 \mathrm{~min}$ & 70 & & 62 & & 46 & & 30 & \\
\hline \multicolumn{9}{|l|}{ Leisure-time exercise per week (\%)† } \\
\hline$>2$ times & 14 & & 17 & & 8 & & 8 & \\
\hline $1-2$ times & 5 & & 9 & & 5 & & 5 & \\
\hline$<1$ time or none & 81 & & 74 & & 87 & & 87 & \\
\hline
\end{tabular}

* Overweight was defined as $\mathrm{BMI} \geq 25$.

† Men $(n)$ : normal weight 427, overweight 174; women $(n)$ : normal weight 390, overweight 214. 
Table 2. Daily intakes of energy, selected nutrients and food items among overweight $\dagger$ and normal-weight subjects in urban Tianjin, China $\S$

(Mean values with their standard errors)

\begin{tabular}{|c|c|c|c|c|c|c|c|c|}
\hline & \multicolumn{4}{|c|}{ Men } & \multicolumn{4}{|c|}{ Women } \\
\hline & \multicolumn{2}{|c|}{ Normal weight } & \multicolumn{2}{|c|}{ Overweight } & \multicolumn{2}{|c|}{ Normal weight } & \multicolumn{2}{|c|}{ Overweight } \\
\hline & Mean & SE & Mean & SE & Mean & SE & Mean & SE \\
\hline Subjects $(n)$ & 886 & & 398 & & 857 & & 490 & \\
\hline Energy (kJ) & 10983 & 83 & $11520^{\star \star \star}$ & 140 & 9236 & 75 & $9493^{*}$ & 105 \\
\hline \multicolumn{9}{|l|}{ Protein } \\
\hline g & 90 & 1 & $94^{*}$ & 1 & 77 & 1 & 78 & 1 \\
\hline$\%$ Energy & $13 \cdot 8$ & 0 & $13 \cdot 7$ & 0 & 13.9 & 0 & $13 \cdot 8$ & 0 \\
\hline \multicolumn{9}{|l|}{ Fat } \\
\hline g & 88 & 1 & $93^{\star *}$ & 1 & 76 & 1 & 78 & 1 \\
\hline \% Energy & $29 \cdot 7$ & 0 & $30 \cdot 3$ & 0 & 31.4 & 0 & $30 \cdot 3^{*}$ & 0 \\
\hline \multicolumn{9}{|l|}{ Carbohydrate } \\
\hline $\mathrm{g}$ & 357 & 2 & $371^{\star *}$ & 4 & 300 & 3 & $315^{\star \star *}$ & 4 \\
\hline \% Energy & 56.5 & 0 & $55 \cdot 9$ & 0 & 54.7 & 0 & $55 \cdot 8^{\star \star}$ & 0 \\
\hline Cereal products (g) & 364 & 4 & $381^{*}$ & 6 & 313 & 4 & $326^{\star \star *}$ & 5 \\
\hline Vegetables $(\mathrm{g})$ & 326 & 7 & 347 & 10 & 321 & 10 & 337 & 14 \\
\hline Potatoes and roots $(\mathrm{g})$ & 37 & 2 & 31 & 3 & 40 & 2 & 37 & 3 \\
\hline Fruits $(g)$ & 86 & 4 & 88 & 7 & 88 & 5 & 100 & 7 \\
\hline Meat products (g) & 99 & 3 & 103 & 4 & 87 & 2 & 87 & 3 \\
\hline Eggs (g) & 55 & 2 & 60 & 2 & 52 & 2 & 56 & 2 \\
\hline Fish $(\mathrm{g})$ & 58 & 2 & 48 & 4 & 51 & 2 & 54 & 3 \\
\hline Oil (g) & 28 & 1 & 30 & 1 & 27 & 1 & $30^{*}$ & 1 \\
\hline Nuts (g) & 7 & 1 & $10^{*}$ & 1 & 6 & 1 & 7 & 1 \\
\hline Sugar (g) & 4 & 0 & 4 & 0 & 3 & 0 & $4^{*}$ & 0 \\
\hline Alcohol (ml) & 8 & 1 & 10 & 1 & 3 & 0 & 2 & 1 \\
\hline
\end{tabular}

Mean values were significantly different from those of normal-weight groups: ${ }^{\star} P<0.05,{ }^{\star \star} P<0.01,{ }^{* \star} P<0.001$.

†Overweight was defined as $\mathrm{BMI} \geq 25$.

‡For details of subjects and procedures, see Table 1 and p. 92.

$\S$ Analyses were made by general factorial ANOVA. Age, energy, education, income, marital status, occupation, and time of survey were adjusted.

a $38 \%$ increased probability of being overweight compared with non-alcohol users. The odds ratio was 1.38 (95\% CI 1.03, 1.84).

Age and marital status were positively associated with overweight among both genders (Table 4). Subjects with $7-12$ years education were more likely to be overweight compared with those with less than 6 years education. Occupational activity was inversely related to overweight among both genders $(P<0.05$ for trend). Men commuting on foot or by bicycle and women going to and from work on foot $\geq 30 \mathrm{~min}$ or by bicycle $\geq 15 \mathrm{~min}$ were about $50 \%$ less likely to be overweight compared with those going to and from work by bus. Men who smoked had a more than $30 \%$ decreased probability of being overweight compared with non-smoking men. Women who smoked had a $50 \%$ decrease.

Table 3. Energy and selected nutrient intakes among overweight* and normal-weight subjects in urban Tianjin, China†

(Adjusted univariate odds ratios and $95 \%$ confidence intervals)

\begin{tabular}{|c|c|c|c|c|}
\hline & \multicolumn{2}{|c|}{ Men } & \multicolumn{2}{|c|}{ Women } \\
\hline & Odds ratio & $95 \% \mathrm{Cl}$ & Odds ratio & $95 \% \mathrm{Cl}$ \\
\hline Energy (418 kJ (100 kcal)) & 1.04 & $1.02,1.06$ & 1.02 & $1.02,1.05$ \\
\hline Protein $(10 \mathrm{~g})$ & 1.06 & $1.01,1.10$ & 1.03 & $0.99,1.08$ \\
\hline Total fat $(10 \mathrm{~g})$ & 1.06 & $1.02,1.10$ & 1.00 & $0.99,1.03$ \\
\hline $\begin{array}{l}\text { Carbohydrate }(10 \mathrm{~g}) \\
\text { Alcohol use }\end{array}$ & 1.02 & $1.01,1.04$ & 1.02 & $1.01,1.04$ \\
\hline No§ & 1.00 & & 1.00 & \\
\hline Yes & 1.38 & $1.03,1.84$ & 0.87 & $0.59,1.30$ \\
\hline
\end{tabular}

* Overweight was defined as $\mathrm{BMI} \geq 25$.

†For details of subjects and procedures, see Table 1 and p. 92.

$\ddagger$ Analyses were made by logistics regression. Age, energy, education, income, marital status, occupation, and time of survey were adjusted.

$\S$ Reference category for calculation of odds ratio. 
Table 4. Non-dietary factors among overweight $\dagger$ and normal-weight populations in urban Tianjin, Chinał§

(Adjusted odds ratios and 95\% confidence intervals)

\begin{tabular}{|c|c|c|c|c|}
\hline & \multicolumn{2}{|c|}{ Men } & \multicolumn{2}{|c|}{ Women } \\
\hline & Odds ratio & $95 \% \mathrm{Cl}$ & Odds ratio & $95 \% \mathrm{Cl}$ \\
\hline Age (years) & 1.02 & $1.01,1.03$ & 1.04 & $1.02,1.05$ \\
\hline \multicolumn{5}{|l|}{ Education (years) } \\
\hline $0-6 \|$ & 1.00 & & 1.00 & \\
\hline $7-12$ & 1.57 & $1 \cdot 10,2 \cdot 23$ & 1.82 & $1 \cdot 32,2 \cdot 52$ \\
\hline$>13$ & 0.99 & $0.61,1.61$ & 1.33 & $0.74,2.39$ \\
\hline Trend & $* *$ & & $* *$ & \\
\hline \multicolumn{5}{|l|}{ Income } \\
\hline Low\| & 1.00 & & 1.00 & \\
\hline Medium & $1 \cdot 31$ & $0.84,2.02$ & 1.04 & $0.30,1.59$ \\
\hline High & 1.32 & $0.87,2.01$ & 0.98 & $0.64,1.49$ \\
\hline Trend & NS & & NS & \\
\hline \multicolumn{5}{|l|}{ Marital status } \\
\hline Single & 1.00 & & 1.00 & \\
\hline Married & $3 \cdot 70$ & $2 \cdot 23,6 \cdot 12$ & $2 \cdot 36$ & $1.59,3.49$ \\
\hline \multicolumn{5}{|l|}{ Occupation } \\
\hline Sedentary\| & 1.00 & & 1.00 & \\
\hline Intermediate & 0.33 & $0.18,0.61$ & 0.99 & $0.64,1.04$ \\
\hline Active & 0.72 & $0.51,0.94$ & 0.73 & $0.56,0.96$ \\
\hline Trend & 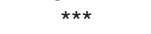 & & * & \\
\hline \multicolumn{5}{|l|}{ Smoking } \\
\hline Noll & 1.00 & & 1.00 & \\
\hline Yes & 0.64 & $0.45,0.91$ & 0.47 & $0.30,0.74$ \\
\hline \multicolumn{5}{|l|}{ Going to and from work each day } \\
\hline By bus $\|$ & 1.00 & & 1.00 & \\
\hline On foot $<30 \mathrm{~min}$ or by bicycle $<15 \mathrm{~min}$ & 0.50 & $0.29,0.80$ & $1 \cdot 32$ & $0.89,1.96$ \\
\hline On foot $\geq 30 \mathrm{~min}$ or by bicycle $\geq 15 \mathrm{~min}$ & 0.48 & $0.31,0.76$ & 0.57 & $0.39,0.84$ \\
\hline Trend & $\star *$ & & 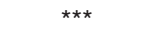 & \\
\hline \multicolumn{5}{|l|}{ Leisure time exercise per week } \\
\hline$<1$ time or nonell & 1.00 & & 1.00 & \\
\hline $1-2$ times & 1.34 & $0.76,2.31$ & 0.94 & $0.51,1.73$ \\
\hline$>2$ times & $1 \cdot 11$ & $0.69,1.80$ & 0.67 & $0.26,1.73$ \\
\hline Trend & NS & & NS & \\
\hline
\end{tabular}

Odds ratios were significantly different among different categories: ${ }^{\star} P<0.05,{ }^{\star \star} P<0.01,{ }^{\star \star *} P<0.001$.

† Overweight was defined as BMI $\geq 25$.

$\ddagger$ For details of subjects and procedures, see Table 1 and p. 92.

$\S$ Analyses were made by logistics regression.

\|l Reference category for calculation of odds ratio.

\section{Discussion}

A Na intervention programme was carried out in part of the areas investigated during the study period. A significant reduction in mean $\mathrm{Na}$ intake and a significant net reduction in systolic blood pressure were shown in the intervention area. There were no significant changes in body weight and in K intake. (Tian et al. 1995a). Since the intervention programme may be the basis for the variables studied, the mean of daily intake of food, energy and the major nutrients, and percentages of SES, overweight and smoking were compared between two study years. There were no significant differences in most of the variables studied. The most likely cause of this is that some of the subjects investigated, but not all, were involved in the intervention project.

Food weighing plus consecutive $3 \mathrm{~d}$ food records were used in the present study to assess dietary intake. Individual food intake was adjusted by the weighing data. Therefore, the method provides a more accurate estimate of individual intake than $24 \mathrm{~h}$ food records only. The limitation of collection of dietary data by this method is that it is labour intensive and time-consuming. Since daily intake of nutrients is variable, using cross-sectional nutritional surveys, especially $24 \mathrm{~h}$ food records, may attenuate the associations between dietary factors and BMI. Individual dietary habits are influenced by a host of social, cultural, customary and economic factors, thus assessments of diet in a relatively homogeneous population may weaken the association between diet and disease. Paeratakul et al. (1998b) evaluated the effect of measurement error in dietary data on the relationship between diet and BMI. They have found that within-person error substantially attenuated the diet-BMI association, and that one way to reduce such attenuation was to use the average of replicate measurements of diet. When the average of three dietary recalls was used instead of a single $24 \mathrm{~h}$ recall, the regression coefficient of fat intake increased by twofold and that of energy intake increased by about $40 \%$.

One study has reported that total energy is positively associated with weight gain (Parker et al. 1997). A metaanalysis, based on nineteen controlled, ad libitum, lowfat, 2-12-month intervention studies, showed that a 
reduction in dietary fat without restriction of total energy intake causes weight loss. The effect is more pronounced in subjects with higher initial body weight (Astrup et al. 2000). Another review, based on animal and clinical research from controlled trials and from epidemiologic and ecologic analysis, also supports the notion that dietary fat plays a role in the development of obesity (Bray \& Popkin, 1998). A Chinese cross-sectional study has indicated that both energy and fat intakes were positively associated with BMI among adult men, but only energy intake was positively related to BMI among women (Paeretakul et al. 1998a). The expected association between dietary factors and different body weight patterns was found in our present study. The present study is consistent with the current literature pertaining to energy intake and BMI among both genders, and to dietary fat intake and BMI among men. Higher carbohydrate intake among both genders, especially from cereal products, as well as higher protein and fat intake in men, and higher oil and sugar intake in women may be the main determinants of higher energy intake among overweight people than normal-weight persons. An increased oil consumption, but not overall fat intake, was shown in the overweight women. The possible reason was that overweight women had no significantly increased intake of other fatty foods such as meat products, eggs, nuts and fish. The higher intakes of energy and carbohydrate were major dietary risk factors among overweight people. Daily higher dietary fat intake was also a risk factor among overweight men. The $\%$ energy from fat was about $30 \%$ in the whole population. It has been suggested by the WHO that the \% energy from fat should be 15-30 (World Health Organization, 1990), and the Chinese recommendation is $20-25 \%$ (National Nutrition Association, 1988).

Diet is one of the most important determinants of body weight. However, some non-dietary factors such as SES, physical activity and smoking also influence body weight in the population. Some studies have shown that overweight or obesity is inversely associated with SES in developed countries, particularly among women, but is positively related to SES in populations of developing countries (Sobal \& Stunkard, 1989; Seidell, 1995; World Health Organization, 1998). The increasing prevalence of overweight or obesity after marriage has been demonstrated in developed countries and in China (Seidell, 1995; Paeratakul et al. 1998a). In the present study, results from education and marital status support those conclusions from developing countries. No significant differences were shown between income and BMI, which disagreed with another Chinese study (Paeratakul et al. 1998a). The small difference of income level between normal and overweight individuals may be the main reason. Since SES may influence dietary intake, we take SES as a confounding variable in the analysis of the association between diet and different weight patterns.

Few studies have demonstrated associations between occupational, commuting physical activity and BMI. Stender et al. (1993) reported a higher BMI in German men with a higher activity level in their jobs compared with inactive men. A study by Paeratakul et al. (1998a) has indicated that occupational physical activity was inversely associated with BMI among Chinese adults. Bovens et al. (1993) have shown a negative correlation between bicycling and BMI among physically active Dutchmen. Most cross-sectional studies have confirmed that a higher level of leisure-time physical activity is related to low BMI (Helmert et al. 1994; Hong et al. 1994; Mensink et al. 1998). The present study showed a strong inverse relationship between occupational physical activity and overweight among both genders. Commuting physical activity on foot or by bicycle was associated with less incidence of overweight among both genders. No relationship between leisure-time exercise and overweight was found in this present study. Daily commuting has traditionally been one of the major forms of physical activity in China. In urban Tianjin, more than $90 \%$ of people use a bicycle or walk to and from work, school, and shopping each day (Hu, 2001). Very few people have private cars. These Chinese people obtain health benefits from their commuting physical activity.

A recent study of the influence of smoking cessation on the prevalence of overweight in the USA pointed out that smoking cessation may be associated with a small increase in the prevalence of overweight, although its benefits are undeniable (Flegal et al. 1995). Chinese adult smokers had lower BMI than non-smokers (Paeratakul et al. 1998a). The present study indicated that smoking was inversely associated with overweight among both genders. The results of the present study support those previous studies.

In conclusion, the present study has shown main dietary and non-dietary risk factors for Chinese overweight adults. The results of this study indicate possible public health benefits in decreasing intakes of energy, carbohydrate and fat, and increasing physical activity and changing social and environmental factors in the overweight population.

\section{Acknowledgements}

The study was supported by a grant from Ministry of Public Health, China, a grant from Tianjin Public Health Bureau and a grant from Department of Physiology, University of Kuopio, Finland.

\section{References}

Astrup A, Grunwald GK, Melanson E, Stris W \& Hill JO (2000) The role of low-fat diets in body weight control: a meta-analysis of ad libitum dietary intervention studies. International Journal of Obesity and Related Metabolic Disorders 24, 1545-1552.

Bovens AM, Baak MA, Verncken JG, Wijnen JA, Saris WH \& Verstappen FT (1993) Physical activity, fitness, and selected risk factors for CHD in active men and women. Medicine and Science in Sports and Exercise 25, 572-576.

Bray GA \& Popkin BM (1998) Dietary fat intake does affect obesity! American Journal of Clinical Nutrition 67, $1157-1173$.

Cheng TO (1998) Cardiovascular diseases in China. Nature Medicine 4, 1209-1210.

Flegal KM, Troiano RP, Pamuk ER, Kuczmarski RJ \& Campbell SM (1995) The influence of smoking cessation on the 
prevalence of overweight in the United States. New England Journal of Medicine 333, 1165-1170.

Helmert U, Herman B \& Shea S (1994) Moderate and vigorous leisure-time physical activity and cardiovascular disease risk factors in West Germany 1984-1991. International Journal of Epidemiology 23, 285-292.

Hong Y, Bots ML, Pan XW, Wang HZ, Jing HG, Hofman A \& Chen HZ (1994) Physical activity and cardiovascular risk factors in rural Shanghai, China. International Journal of Epidemiology 23, 1154-1158.

Hu G (2001) Physical activity during commuting and recreation associated with cardiovascular risk factors in China. $\mathrm{PhD}$ Thesis, University of Kuopio.

Hubert HB, Feinlieb M, McNamara PM \& Castelli WP (1983) Obesity as an independent risk factor for cardiovascular disease: a 26 year follow-up of participants in the Framingham heart study. Circulation 67, 968-977.

Mensink GB, Ziese T \& Kok FJ (1998) Benefits of leisure time physical activity on the cardiovascular risk profiles at older age. International Journal of Epidemiology 28, 659-666.

Mertens IL \& Gaal LF (2000) Overweight, obesity, and blood pressure: the effect of modest weight reduction. Obesity Research 8, 270-278.

National Nutrition Association (1988) Recommended Dietary Allowances. Beijing: Public Health Press (in Chinese).

Paeratakul S, Popkin BM, Ge KY, Adair L \& Stevens J (1998a) Change in diet and physical activity affect the body mass index of Chinese adults. International Journal of Obesity and Related Metabolic Disorders 22, 424-431.

Paeratakul S, Popkin BM, Kohlmeier L, Hertz-Picciotto I, Guo X \& Edwards LJ (1998b) Measurement error in dietary data: Implications for the epidemiologic study of the diet-disease relationship. European Journal of Clinical Nutrition 52, $722-727$.

Parker DR, Gonzalez S \& Derby CA (1997) Dietary factors in relation to weight change among men and women from two south-eastern New England communities. International Journal of Obesity and Related Metabolic Disorders 21, 103-109.

Popkin BM, Paeratakul S, Ge K \& Zhai F (1975) Body weight patterns among the Chinese: results from the 1989 and 1991 China Health and Nutrition Surveys. American Journal of Public Health 85, 690-694.
Preventive Medicine Academy of China (1991) Food Composition Tables. Beijing: Public Health Press (in Chinese).

Reddy KS \& Yusuf S (1998) Emerging epidemic of cardiovascular disease in developing countries. Circulation 97, 596-601.

Seidell JC (1995) Obesity in Europe: scaling an epidemic. International Journal of Obesity and Related Metabolic Disorders 19, S1-S4.

Sobal J \& Stunkard AJ (1989) Socioeconomic status and obesity: a review of the literature. Psychological Bulletin 105, 260-275.

Stender M, Hense HW, Doring A \& Keil AU (1993) Physical activity at work and cardiovascular disease risk: results from the MONICA Augsburg study. International Journal of Epidemiology 22, 644-650.

Stunkard AJ (1996) Current views on obesity. American Journal of Medicine 100, 230-236.

Tian HG, Guo Z, Hu G, Yu Z, Sun W, Pietinen P \& Nissinen A (1995a) Changes in sodium intake and blood pressure in a community-based intervention project in China. Journal of Human Hypertension 9, 959-968.

Tian HG, Nan Y, Hu G, Dong Q, Yang X, Pietinen P \& Nissinen A (1995b) Dietary survey in a Chinese population. European Journal of Clinical Nutrition 49, 26-32.

Tianjin Public Health Bureau (1993) A Brief Introduction to Tianjin Four Diseases Program 1984-1992. Tianjin: Tianjin Public Health Bureau (in Chinese).

World Health Organization (1990) Diet, Nutrition, And Prevention of Chronic Diseases. World Health Organization Technical Report Series no. 797. Geneva: WHO.

World Health Organization (1998) Obesity: Preventing and Managing the Global Epidemic. pp. 130-132. Geneva: WHO.

Wood PD (1994) Physical activity, diet, and health independent and interactive effects. Medicine and Science in Sports and Exercise 26, 838-843.

Yao C, Wu Z \& Wu Y (1993) The changing pattern of cardiovascular diseases in China. World Health Statistics Quarterly 46, $113-118$.

Yu ZJ, Song GD, Guo ZY, Zheng GW, Tian HG, Vartiainen F, Puska P \& Nissinen A (1999) Changes in blood pressure, body mass index and salt consumption in a Chinese population. Preventive Medicine 29, 165-172. 